\title{
Inflation Instability Impact on Interest Rate in Egypt: Augmented Fisher Hypothesis Test
}

\author{
Doaa Akl Ahmed ${ }^{1,2}$, Mamdouh Abdelmoula M. Abdelsalam ${ }^{3}$ \\ ${ }^{1}$ Department of Economics, Benha university, Egypt \\ ${ }^{2}$ Department of Economics, Future University, Egypt \\ ${ }^{3}$ Department of Economics, Menoufia University, Egypt. E-mail: mamdouh.abd@commerce.menofia.edu.eg \\ Correspondence: Doaa Akl Ahmed, Department of Economics, Benha university, Benha, Egypt. E-mail: \\ doaa.ahmed01@fcom.bu.edu.eg.
}

Received: October 18, 2017

Accepted: November 13, $2017 \quad$ Available online: November 30, 2017

doi:10.11114/aef.v5i1.2709

URL: https://doi.org/10.11114/aef.v5i1.2709

\begin{abstract}
The paper aims at examining an augmented version of Fisher hypothesis that include inflation instability. According to this hypothesis, there is a positive relation between interest rates and expected inflation. In contrast, there is a debate regarding the impact of inflation uncertainty on interest rate. According to the portfolio theory and models of asset pricing, inflation instability positively affects the interest rate. The reason is that risk-averse investors must be compensated with higher returns for higher risks. In contrast, the loanable funds theory implies a negative impact of inflation instability and interest rates since high uncertainty leads consumers to protect themselves against inflation by raising their savings which lowers consumption and interest rates. To compute inflation volatility, we applied different Autoregressive Conditional Heteroscedasticity models. The simple and augmented versions of Fisher hypothesis are examined using Markov Switch Model to account for possible regime shift in that relationship. For the original Fisher hypothesis, there is an evidence of supporting it in the first regime while that hypothesis does not hold in the second one. In the augmented version of Fisher hypothesis, portfolio theory hypothesis is verified in the first regime whereas the loanable funds hypothesis is confirmed in the second one.
\end{abstract}

Keywords: monetary policy, interest rates, inflation uncertainty, nonlinear models

JEL Classifications: C32, E31, E52.

\section{Introduction}

There is a great consensus between economists that unexpected inflation has major impacts on the macroeconomic performance. Unstable inflation leads to postponing the decisions of investment and decreases the purchasing power which implies a lower demand and lower growth rates. Based on that, many central banks around the world adopted price stability as the primary objective of their monetary policy keeping in mind the negative consequences inflation uncertainty on the economy (Javed and Khan, 2010; Bhar and Mallik, 2012). Therefore, a numerous literature studied the relationship between inflation instability and various aspects of macroeconomic variables including output, inflation and interest rate. Concerning the influence of inflation uncertainty on output, Dotsey and Sarte (2000) provide an evidence of a negative long-run relationship between inflation variability and real growth. Elder (2000) reports that higher inflation uncertainty reduces output growth. This negative link between the abovementioned two variables were also confirmed by other studies (Wilson and Culver, 1999; Grier and Perry, 2000; Hayford 2000; Fountas et al., 2002; and Grier et al., 2004; Wilson, 2006). In contrast, Levin and Renelt (1992), Levin and Zervos (1993) and Clark (1997) found that instability of inflation does not influence output growth.

Concerning the relation between inflation and its instability, there is a debate about both the type and the direction of this relation. According to Friedman (1977)-Ball (1992) hypothesis, inflation has a positive impact on uncertainty. This hypothesis is supported by many empirical literatures including Hess (1993); Grier and Perry (1998); Fountas, Ioannidis and Karanasos (2004). In contrast, Pourgerami and Maskus (1987) and Unger and Zilberfarb (1993) argue that higher inflation should lead to lowering inflation instability as central banks will assign more resources to have accurate forecasts for inflation. Regarding the impact of inflation variability on inflation, Cukierman and Meltzer (1986) 
hypothesises that instability of inflation leads to higher inflation as policymakers try to surprise the public to have economic gains whereas Holland (1995) claims that high inflation instability has a negative impact on inflation rate due the stabilization policy implemented by monetary authorities to face the high uncertainty levels. Empirically, Brunner and Hess (1993) and Grier and Perry (1998) found that the variability of inflation does not influence inflation rate. Further, Fountas, Ioannidis and Karanasos (2004), Karanasos and Schurer (2008), and Thornton (2007) found mixed results depending on the countries studied. Moreover, Živkov, et al. (2014) found that inflation volatility has a positive impact on inflation in the large countries with flexible exchange rate.

Concerning the impact of inflation instability on interest rate, unexpected inflation randomly redistributes wealth against creditors and in favour of debtors. In addition, higher interest rates decrease consumption and investment which lowers economic growth (Bhar and Mallik, 2012). Further, inflation variability influence on interest rates could affect the intertemporal allocation decisions. If inflation volatility positively linked to interest rates, this volatility will have a major impact in reducing economic growth through its negative impact on consumption and investment through interest rate channel (Omay and Hasanov, 2010). According to Blanchard (2003), a rise in interest rates also increase debt burden and increases the volatility of capital flows which impend the stability of the financial sector. In contrast, if inflation instability negatively affects interest rates, then its general impact on economic activity will be imprecise and depends largely on the case under consideration (Omay and Hasanov, 2010).

Theoretically, Fisher (1930) claims that there is a positive relation between interest rates and expected inflation. This link is documented in the literature as Fisher hypothesis. However, there is a disagreement in the economic theory regarding the impact of inflation instability on interest rates. The advocates of Markowitz's (1952) portfolio theory argue that inflation volatility affects nominal interest rates positively. In addition, models of asset pricing models and term structure of interest rates imply a positive link between the aforementioned variables. This could be investigated as risk-averse investors need to be compensated with higher returns in case of higher risks. Conversely, the loanable funds theory states that if the variance of inflation differs from that of nominal income, this will lead to high volatility of real income. Consequently, the consumers will seek to protect themselves against inflation by raising their savings leading to lower consumption and interest rates (Juster and Wachel (1972a, b) and Juster and Taylor (1975). As stated by Stulz (1986), if there is a negative relationship between money growth and real income, a higher level of instability of monetary policy leads to higher anticipated real interest rate and a lower nominal rate.

Mishkin (1992) evidenced that the Fisher hypothesis is held in the USA over the long-term but not in the short-term. In addition, Yuhn (1996) found that a Fisher hypothesis is fulfilled in Germany in the long-run. Additionally, other studies provided an evidence for this positive link between inflation risk and interest rate (e.g. Chan, 1994; Tzavalis and Wickens, 1996; Kandel et al., 1996; and Berument, 1999). On the other hand, other literature reported a negative relationship between inflation uncertainty and nominal interest rate (Bomberger and Frazer, 1981; Zilberfarb, 1989), Sarte, 1998; Jorda and Salyer, 2003).

Berument et al. (2005) investigated this link between inflation variability and interest rates in the UK before and after the inflation targeting regime and supports the notion of inflation targeting regimes. Malik and Bhar (2012) extended the sample of Berument et al. (2005) to include other inflation targeters. They decompose inflation instability into two components - impulse and structural and found a positive link between the expected inflation and interest rates. Further, they show that Structural uncertainty has a positive and significant impact on interest rates for some countries. Furthermore, their results revealed that the long-run effects of inflation on interest rates are less than one after adopting inflation targeting regime indicating the ability of central banks in those countries to conduct a successful monetary policy.

Accordingly, our objective is to estimate a modified version of Fisher hypothesis by allowing inflation volatility to affect the interest rate. Consequently, our hypothesis is that both expected inflation and its instability are positively linked to the interest rate. Our choice of Egypt as a case study is attributed to many reasons that include inflation rate in Egypt is highly volatile which means this relation could be examined. Furthermore, examining the positive link between inflation uncertainty and interest rate is of great interest for policymakers when they attempt to achieve low inflation rates. This could be attributed to the fact that if their deflationary policies are not credible, then, the expected inflation will change less than the realized inflation. This will increase the forecast error, and hence the inflation risk. If the inflation risk affects the interest rate, this might be an alternative transmission mechanism that could explain how contractionary monetary policy decreases the output level.

To generate inflation instability, we used three different specifications of Autoregressive Conditional Heteroscedasticity (ARCH)-type processes. The first ARCH model was first introduced by Engle (1982). Thus, the employed models in this paper include ARCH in mean ARCH(1)-M model, Exponential GARCH in mean $(\operatorname{EGARCH}(1,1,1)-\mathrm{M})$ and asymmetric Power GARCH in mean (APGARCH(1,1,1)-M). According the AIC and SIC criterion, the EGARCH-M model is superior to other counterparts. Thus, we used it to generate both the expected inflation and the risks of inflation. 
To test the both the simple and the augmented versions of Fisher hypothesis, we employed a Markov Switch Model (MSM) that accounts for the existence of regime shifts within the employed dataset. We found that there are two regimes in the data and also the estimated parameters change its sign between different regimes. For the simple Fisher hypothesis model, predicted inflation positive affect interest rate in the first regime while there is no causal link between both variables in the second regime. That is to say, expected inflation is found to be positive and significant in the first regime but it is insignificant in the second one. For the augmented Fisher hypothesis model, inflation forecasts have no influence on interest rate in both regimes. Regarding the impact of inflation uncertainty on interest rate, it is positive in the first regime which supports Markowitz's (1952) portfolio theory whereas it is negative in the second regime which is in favour of the loanable funds hypothesis. These results imply the existence of the nonlinear impact of both expected inflation and inflation uncertainty on interest rate which justifies employing MSM.

The rest of the paper is structured as follow: section two presents the methodology of computing the inflation volatility as well as the MSM that is used to examine the causal link between the studied variables. Section three is devoted to display the data examination and results while section four concludes.

\section{Methodology}

Estimation of inflation instability is highly required for risk averse agents while making their decisions as they concerned with both the expected level of and the calculated risk of inflation. To measure inflation uncertainty, Hafer (1986) and Davis and Kanago (1996) used standard deviation of inflation forecasts while Johnson (2002) uses the absolute value of inflation forecast errors. Using Kalman Filter method to estimate time-varying coefficients of inflation is also recommended by some studies (see for example, Berument et. al., (2007), Darvas and Varga (2009)). Additionally, the second moment of the distribution has been frequently employed as a proxy measure for uncertainty (Markowitz, 1959). Thus, numerous studies employed different specifications of Autoregressive Conditional Heteroscedasticity (ARCH) family models. The basic ARCH model was introduced by Engle in 1982 in which conditional variance is regressed on past squared residual, then, this model is generalized by Bollerslev (1986) to permit the lagged conditional variance to affect current values of conditional variance. Taylor (1986) and Schwert (1989) assumes that the risks could be modeled in terms of the conditional standard deviation instead of the conditional varianc. However, these specifications can capture stylized properties of financial variables such as volatility clustering and persistence, they assume that uncertainty responds symmetrically to negative and positive shocks. Also, these models assume a Gaussian distribution for the error term. To overcome these limitations, Nelson (1991) introduced the exponential GARCH (EGARCH) model that assume a GED distribution for the error term as well as it allows for leverage effect. Ding et al 1993) suggested a new class of models (APGARCH) in which the power term (by which the data are transformed) is estimated within the model instead of being imposed arbitrarily. Thus, this model permits a vast number of transformations inclusive of any positive value which nests a variety of ARCH specifications.

In this paper, we used different specifications of ARCH family model to estimate the inflation uncertainty and then we compared between them using Akaike Information Criterion (AIC) and Schwartz Information Criterion (SIC). Therefore, we used a two-step estimation procedure. First, we generate expected inflation and inflation uncertainty by applying the aforementioned ARCH-type models. Second, these two series are then used as independent variables in the MSM to examine their impact on interest rate. Thus, this section starts by introducing the different models used to estimate expected inflation and inflation volatility, followed by presenting the Fisher hypothesis augmented with inflation instability and end with the MSM that will be used to model the impact of inflation and its instability on interest rate.

\subsection{Modelling Inflation Risks}

To estimate inflation uncertainty, we need to model the inflation process. In this paper, we assumed that inflation rate is dependent on its past values as shown in equation (1). To model conditional variance of financial variables, Engle (1982) introduced the basic ARCH model in which the conditional variance depends on squares of lagged residuals. In this paper, we used ARCH(1)-M model as it appears in equations (1) and (2). In equation (1), inflation $\left(\pi_{t}\right)$ is expressed as a function in its own lags beside the conditional standard deviation $\left(\sqrt{h}_{\mathrm{t}}\right)$. On the other hand, equation (2) regresses conditional variance $\left(h_{t}\right)$ on the past squared errors $\left(\varepsilon_{t-1}^{2}\right)$.

$$
\begin{gathered}
\pi_{t}=\alpha_{0} \sqrt{h}_{\mathrm{t}}+\sum_{i=1}^{p} \alpha_{i} \pi_{t-i}+\varepsilon_{\mathrm{t}} \quad \text { where } \varepsilon_{t} \sim N\left(0, \sigma_{\varepsilon}^{2}\right) \\
h_{t}=\lambda_{0}+\lambda_{1} \varepsilon_{t-1}^{2}
\end{gathered}
$$

Where $\alpha_{i}$ is the coefficient of the ith lag of inflation. To ensure positivity and stationarity of conditional variance, the 
following conditions should be imposed $\left(\lambda_{0} \geq 0,0 \leq \lambda_{1}<1\right)$.

Many different variants of GARCH specifications are then developed to estimate conditional volatility. Bollerslev (1986) extended the ARCH model to its generalized version by permitting the conditional variance to be a function of its lagged values beside past squared errors. To express the $\operatorname{GARCH}(1,1)$ process, the conditional variance is a function of its first lag and the residual squared of the previous month as presented in equation (3).

$$
h_{t}=\lambda_{0}+\lambda_{1} \varepsilon_{t-1}^{2}+\lambda_{2} h_{t-1}
$$

However, the GARCH(p,q) specification does not allow for leverage effect to be modelled. Furthermore, Nelson (1991) proposed an exponential version of GARCH model. The EGARCH $(1,1)$ model presents the conditional variance under a logarithmic form as follows:

$$
\mathrm{H}_{\mathrm{t}}=\lambda_{0}+\lambda_{1}\left|\frac{\varepsilon_{t-1}}{\sqrt{h_{t}}}\right|+\lambda_{2} \mathrm{H}_{\mathrm{t}-1}+\gamma_{1} \frac{\varepsilon_{t-1}}{\sqrt{h_{t}}}
$$

where $H_{t}=\log \left(h_{t}\right)$ and $\varepsilon_{t}$ follows GED distribution with 0 mean and $h_{t}$ conditional variance.

The model is advantageous in comparison with the GARCH specification for many reasons. The EGARCH model uses the logarithm of conditional variance $\log \left(\mathrm{h}_{\mathrm{t}}\right)$ which implies there is no need to impose non-negativity constraints on the parameters $\lambda_{1}$ and $\lambda_{3}$. This is could be explained as even if the parameters are negative, $H_{t}$ will be positive. Concerning the non-explosive property of the conditional volatility, the model assumes that the coefficient of lagged volatility must be less than one (i.e., $\lambda_{2}<1$ ).

Taylor (1986) and Schwert (1989) developed the standard deviation GARCH model which allows to model the conditional standard deviation instead of the conditional volatility. Ding et al. (1993) generalized this model and introduced the asymmetric power $\operatorname{ARCH}(1,1)$ in which the power parameter of the standard deviation can be estimated rather than imposed. In this paper, we employ an asymmetric power $\operatorname{GARCH}(1,1,1)-\mathrm{M}$ (APGARCH(1,1,1)-M) specification as shown in equation (5).

$$
\begin{gathered}
h_{t}^{\tau}=\lambda_{0}+\lambda_{1}\left(\left|\varepsilon_{t-1}\right|-\gamma_{1} \varepsilon_{t-1}\right)^{\tau}+\lambda_{2} h_{t-1}^{\tau} \\
\lambda_{0} \geq 0, \quad \lambda_{1}>0, \quad-1<\gamma_{1}<1 \quad, \quad \lambda_{1} \geq 0 \quad \delta>0
\end{gathered}
$$

Where $\lambda_{1}$ and $\lambda_{2}$ characterize the standard ARCH and GARCH coefficients respectively, $\gamma_{1}$ represents the leverage parameter, and $\tau$ corresponds to the optimal power that plays the role of a Box-Cox transformation of $h_{t}$. A positive value of $\gamma_{1}$ means that past negative shocks have a greater effect on current conditional variance compared to past positive shocks (Haung and Lin, 2004). The latter specificarion of $\operatorname{APGARCH}(1,1)$ model nests some other ARCH models such as the basic $\operatorname{GARCH}(1,1)$ models if $\tau=2$ and $\gamma_{1}=0$.

Based on that, we estimate three different specification of inflation. This is done to generate both expected inflation and inflation volatility. The expected inflation series is calculated as the one-step ahead forecast from equation (1). On the other hand, inflation variance is computed as the conditional variance resulting from the different ARCH-family models (i.e., equations (2), (4) and (5) corresponding to $\mathrm{ARCH}(1)-\mathrm{M}, \operatorname{EGARCH}(1,1,1)-\mathrm{M}$ and $\operatorname{APGARCH}(1,1,1)-\mathrm{M}$ model respectively). Both computed variables will serve as independent variables in the second step.

\subsection{Fisher Hypothesis Augmented with Inflation Instability}

As indicated by Fisher (1930), expected inflation has a positive impact on interest rate. Thus, this relationship could be written as follows:

$$
r_{t}=\theta_{1}+\gamma_{1} \pi_{t+1}^{e}+\epsilon_{t}
$$

Where $r_{t}$ is interest rate, whereas $\pi_{t+1}^{e}$ is expected inflation at time t. In this equation, we have two possible outcomes: If $\gamma_{1}=1$, then a strong form of Fisher hypothesis exists, if $0<\gamma_{1}<1$, then a weak form of Fisher hypothesis exists (Malik and Bhar, 2011). To avoid the problem of misspecification of the interest rate model, we allow lagged interest rate to appear as an explanatory variable as presented in equation (7). Also, this new specification allows for capturing the short-term dynamics of interest rate (Bhar and Malik, 2012).

$$
r_{t}=\theta_{1}+\Theta_{1} r_{t-1}+\gamma_{1} \pi_{t+1}^{e}+\epsilon_{t}
$$

To examine the impact of inflation instability on interest rate we allowed the former to appear as an independent variable in the interest rate equation as illustrates below. In this paper, we employed MSM as one of nonlinear models since these models perform better compared to the linear counterparts in case of using highly volatile data or data that suffer from structural breaks (Hamilton, 1994). MSM was firstly introduced by Goldfield and Quandt (1973) but it 
becomes popular after the publication of Hamilton (1989). The idea of this model is decomposing the underlying data into a finite sequence of distinct regimes. Then, for each regime there is a specific regression and fitting values. Thus, the model is linear inside each separate regime but overall it is nonlinear inside different regime.

Suppose that our aim is to analyse a specific variable, $Y_{t}$. The functional form of $Y_{t}$ can be expressed by using MSM as following:

$$
Y_{t}= \begin{cases}\beta_{1} Z_{t}+\varepsilon_{1 t} & \text { if } S_{t}=1 \\ \beta_{2} Z_{t}+\varepsilon_{2 t} & \text { if } S_{t}=2\end{cases}
$$

Where $Y_{t}$ is the considered dependent variable, in our case it is the treasury bills interest rate, $Z_{t}$ is a vector of explanatory variables, $\beta_{i}$ is a vector of coefficients, which should be estimated based on non-observable state variable $S_{t}$ and finally, $\varepsilon_{i t}$ is Gaussian white noise error term which can be different for each regime as in our case. $S_{t}$ follows a first order Markov-process and it is modelled by using the matrix $\Pi$ that includes the transition probabilities $P_{i j}$ from the first regime $i$ to the second regime $\mathrm{j}$ as following:

$$
\Pi=\left[\begin{array}{ll}
p_{11} & p_{12} \\
p_{21} & p_{22}
\end{array}\right], p_{i j}=\operatorname{pr}\left(S_{t}=j \mid S_{t-1}=i\right)
$$

Once the required coefficients and the transition matrix are estimated, the probability $\operatorname{pr}\left(S_{t}=j \mid r_{1}, \ldots, r_{T}\right)$ of being in state $\mathrm{j}$ depending on the prevailed knowledge in the model can be counted for each specific point of time. If the estimated probabilities are calculated based on the prevailed information till the point $\mathrm{t}, \operatorname{pr}\left(S_{t}=j \mid r_{1}, \ldots, r_{t}\right)$ this is defined as smoothed probabilities. However, if the probabilities are calculated based on the prevailed information till the point $\mathrm{t}-1, \operatorname{pr}\left(S_{t}=j \mid r_{1}, \ldots, r_{t-1}\right)$ this is defined as filtered probabilities.

In the current study, the vector $Z_{t}$ includes the first lag of interest rate, $r_{t-1}$, the uncertainty of inflation which is generated from the first step $h_{t}$ and the prediction of inflation $\pi_{t+1}^{e}$ which is generated from the first step. Thus, the relationship can be written in the following form:

$$
r_{t}= \begin{cases}\theta_{1}+\Theta_{1} r_{t-1}+\omega_{1} h_{t}+\gamma_{1} \pi_{t+1}^{e}+\epsilon_{1 t} & \text { if } S_{t}=1 \\ \theta_{2}+\Theta_{2} r_{t-1}+\omega_{2} h_{t}+\gamma_{2} \pi_{t+1}^{e}+\epsilon_{2 t} & \text { if } S_{t}=2\end{cases}
$$

Where $h_{t}$ and $\pi_{t+1}^{e}$ are uncertainty of inflation and the predicted inflation from the first step respectively. The parameters, $\theta_{1}, \Theta_{1}, \omega_{1}$ and $\gamma_{1}$ reflect the attitude of the underlying variable in the first regime. Similarly, the parameters, $\theta_{2}, \Theta_{2}, \omega_{2}$ and $\gamma_{2}$ reflect the attitude of the underlying variable in the second regime. In addition, $\epsilon_{1 t}$ and $\epsilon_{2 t}$ are the errors in the first and the second regimes which is assumed to be different and they follow normal distribution.

Then, as discussed by Hamilton (1989) in order to estimate MSM based on the probabilistic inference associated the state variable; $S_{t}$, the estimated probabilities can be transferred into the general likelihood function of the data and then the required likelihood function can be estimated by utilising one of the optimization techniques. As mentioned before, each regime has a specific regression, then, for a given regime $(\mathrm{m})$, the conditional mean for $Y_{t}$ is based on the assumption of linearity. Then, if $X_{t}$ is the regressor, the dependent variable conditional mean for each regime $m$ can be expressed in the form:

$$
\mu_{t}(m)=X_{t}^{\prime} \beta_{m}
$$

Where, $\beta_{m}$ is the parameters associated for each regime $\mathrm{m}$.

The likelihood value for each observation is counted by taking the density function weighted average for the prediction of one step ahead with the assumption of each regime is the proper one as following:

$$
\mathcal{L}_{t}(\beta, \sigma, \delta)=\sum_{m=1}^{2} \frac{1}{\sigma} \phi\left(\frac{Y_{t}-\mu_{t}(m)}{\sigma}\right) \cdot P\left(S_{t}=m \mid \xi_{t-1}, \delta\right)
$$

Where $\beta=\left(\beta_{1}, \beta_{2}\right)$ are estimated parameters, $\sigma$ is the variance, $\delta$ refers to the probability estimated for each regime, $\xi_{t-1}$ denotes the information set in the previous period $\mathrm{t}-1$, and $\phi$ denotes the standard normal distribution. Then, the normal mixture distribution mixture function can be utilised to estimate the whole log likelihood function: 


$$
\ell(\beta, \sigma, \delta)=\sum_{t=1}^{T} \log \left\{\sum_{m=1}^{2} \frac{1}{\sigma} \phi\left(\frac{Y_{t}-\mu_{t}(m)}{\sigma}\right) \cdot P\left(s_{t}=m \mid \xi_{t-1}, \delta\right)\right\}
$$

In order to test for the reliability of the MSM against the traditional linear regression model could be conducted based on Wald test as in Engle and Hamilton (1990). The Wald test allows for the testing against the null hypothesis of the same values for different coefficients in the two regimes.

Lastly, to check for the prediction power of inflation uncertainty when we predict interest rate, we forecast interest rate with and without inflation uncertainty variable from MSM.

\section{Data and Results}

\subsection{Data Sources and Preliminary Examination}

We use monthly data for monthly CPI inflation rate $\left(\pi_{t}\right)$ and treasury bills interest rate $\left(r_{t}\right)$ that ranges from January 1997 to March 2017. The dataset is collected from International Monetary Fund-International Financial Statistics. The sample size is selected based on data availability since the Treasury bill interest rate data was initially published in January 1997. Figure (1) shows the development of inflation and interest rate through the period under investigation. As shown in the graph, inflation data is volatile which imply that it is instable and this instability may have an influence on interest rate. The first step of check is to test for the stationarity of data, therefore we employed Phillips-Perron test that reveals that the unit root hypothesis is rejected at $1 \%$ level of significance as shown in table (1).

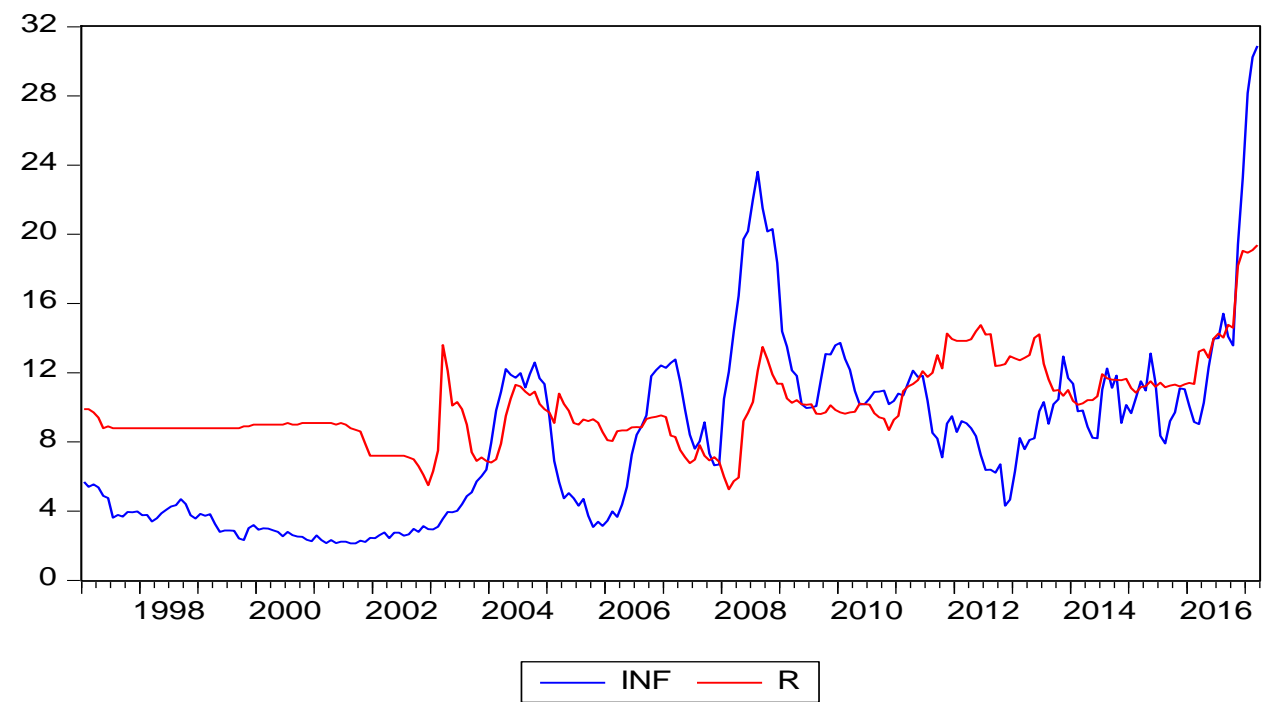

Figure (1). Monthly Inflation and Interest Rate in Egypt from 1997:1 to 2017:3

Table (1). Probabilities of Phillips-Perron unit root test

\begin{tabular}{cc}
\hline Variable & Phillips-Perron test \\
\hline$r_{t}$ & 0.0092 \\
$\pi_{t}$ & 0.0046 \\
\hline
\end{tabular}

The second step in our technique is to generate the series of inflation uncertainty by modelling the autoregressive inflation inside different ARCH-type models. Specifically, we modelled inflation by using three variant versions of ARCH family models: ARCH(1)-M model with student-t distribution, EGARCH(1,1,1)-M with GED distribution and APGARCH(1,1,1)-M with GED. Table (2) displays the estimates of the aforementioned models along with the diagnostic tests. In our model, inflation rate is regressed on its first lag as well as the conditional standard deviation. The results reveal that the estimated conditional standard deviation parameter in mean equation $\alpha_{0}$ is positive and significant in EGARCH(1,1,1)-M and APGARCH(1,1,1)-M models while it is positive but insignificant in ARCH(1) model. With respect to the parameter of lagged volatility $\left(\lambda_{2}\right)$, it is positive and significant in both EGARCH( $\left.1,1,1\right)$-M and $\operatorname{APGARCH}(1,1,1)-\mathrm{M}$.

According to both AIC and SIC, the EGARCH(1,1,1)-M specification outperforms its counterparts. As mentioned earlier, the EGARCH models uses the logarithm of conditional volatility $\log \left(h_{t}\right)$ which is favourable to other models in terms of imposing no restrictions on the sign of the estimated parameters $\lambda_{1}$ and $\lambda_{2}$. Furthermore, the model assumes that $\lambda_{2}$ must be lower than 1 to assure the stationarity of the conditional variance. As shown in table (2), the estimated value of $\lambda_{2}$ satisfies the stationarity condition. Moreover, given that the estimated value of $\lambda_{2}$ approaches 
one which implies the existence of high degree of instability persistence in the inflation rate.

The L-Jung-Box Q statistic shows that the sequences of residuals and the squared residuals are free from autocorrelation. To ensure that the estimated model is free of any heteroscedasticity effects, we performed the ARCH-LM tests for the inflation equation. Therefore, the squared residuals from equation (1) are regressed on its 3, 6, 9, and 12 lags for the employed sample. The lower part of table (2) displays the p-values of the ARCH-LM test statistic $\left(\chi^{2}\right)$ crossponding to the aforementioned lags. According to these probabilities, we can conclude that the null hypothesis of no heteroscedasticity cannot be rejected, and we can use the estimated model to calculate the time-varying conditional uncertainty of inflation.

Table (2). Estimates of the selected EGARCH model

\begin{tabular}{|c|c|c|c|c|c|c|}
\hline \multirow[b]{2}{*}{ Parameter } & \multicolumn{2}{|c|}{ ARCH(1)-M } & \multicolumn{2}{|c|}{ EGARCH(1,11)-M } & \multicolumn{2}{|c|}{ APGARCH(1,1,1)-M } \\
\hline & Estimates & $\begin{array}{c}\text { Z-Stat. } \\
\text { (Standard } \\
\text { Error) }\end{array}$ & Estimates & $\begin{array}{c}\text { Z-Stat. } \\
\text { (Standard } \\
\text { Error) } \\
\end{array}$ & Estimates & $\begin{array}{c}\text { Z-Stat. } \\
\text { (Standard } \\
\text { Error) } \\
\end{array}$ \\
\hline & \multicolumn{6}{|c|}{ Mean Equation } \\
\hline$\alpha_{0}$ & 0.074766 & $\begin{array}{l}0.704177 \\
(0.10617) \\
\end{array}$ & 1.354391 & $\begin{array}{r}2.190705 \\
(0.61824) \\
\end{array}$ & 0.304614 & $\begin{array}{l}63.11081 \\
(0.00482) \\
\end{array}$ \\
\hline \multirow[t]{2}{*}{$\alpha_{1}$} & 0.986233 & $\begin{array}{r}102.7404 \\
(0.00959) \\
\end{array}$ & 0.843694 & $\begin{array}{r}11.61873 \\
(0.07261) \\
\end{array}$ & 0.974075 & $\begin{array}{l}624.7429 \\
(0.00155) \\
\end{array}$ \\
\hline & \multicolumn{6}{|c|}{ Variance Equation } \\
\hline$\lambda_{0}$ & 0.441211 & $\begin{array}{l}7.639842 \\
(0.05775)\end{array}$ & -0.18612 & $\begin{array}{c}-2.4474 \\
(0.07604)\end{array}$ & 0.070492 & $\begin{array}{c}45.7133 \\
(0.00154)\end{array}$ \\
\hline$\lambda_{1}$ & 0.700959 & $\begin{array}{l}3.626097 \\
(0.19331) \\
\end{array}$ & 0.245794 & $\begin{array}{c}2.45621 \\
(0.10007) \\
\end{array}$ & 0.200951 & $\begin{array}{l}32.56463 \\
(0.00617)\end{array}$ \\
\hline$\lambda_{2}$ & & & 0.981511 & $\begin{array}{l}70.36014 \\
(0.01395) \\
\end{array}$ & 0.733200 & $\begin{array}{c}158.524 \\
(0.00462) \\
\end{array}$ \\
\hline$\gamma_{1}$ & & & 0.244103 & $\begin{array}{l}5.040943 \\
(0.04842) \\
\end{array}$ & -0.08025 & $\begin{array}{l}-25.8073 \\
(0.00311)\end{array}$ \\
\hline$\tau$ & & & & & 0.027190 & $\begin{array}{r}8.028349 \\
(0.00338)\end{array}$ \\
\hline AIC & \multicolumn{2}{|c|}{2.759099} & \multicolumn{2}{|c|}{2.365585} & \multicolumn{2}{|c|}{2.706042} \\
\hline SIC & \multicolumn{2}{|c|}{2.816598} & \multicolumn{2}{|c|}{2.451833} & \multicolumn{2}{|c|}{2.806665} \\
\hline Log Likelihood & \multicolumn{2}{|c|}{-331.2305} & \multicolumn{2}{|c|}{-281.4186} & \multicolumn{2}{|c|}{-321.7841} \\
\hline \multicolumn{7}{|c|}{ L-Jung-Box Q-Stat for lag (10) } \\
\hline Residuals & 12.677 & $0.242 *$ & 12.436 & $0.257 *$ & 12.529 & $0.325 *$ \\
\hline $\begin{array}{l}\text { Squared } \\
\text { Residuals }\end{array}$ & 2.8022 & $0.986^{*}$ & 3.1446 & $0.978^{*}$ & 3.8048 & $0.956^{*}$ \\
\hline \multicolumn{7}{|c|}{ ARCH LM test } \\
\hline & Obs $\mathbf{R}^{2}$ & $\begin{array}{c}\text { Prob. Of } \\
\chi^{2}\end{array}$ & Obs $\mathbf{R}^{2}$ & $\begin{array}{c}\text { Prob. Of } \\
\chi^{2}\end{array}$ & $\operatorname{Obs} \mathbf{R}^{2}$ & $\begin{array}{l}\text { Prob. Of } \\
\chi^{2}\end{array}$ \\
\hline ARCH-LM(3) & 1.091906 & 0.779 & 0.8440 & 0.8440 & 1.308290 & 0.7272 \\
\hline ARCH-LM(6) & 2.990436 & 0.8100 & 1.853711 & 0.9326 & 2.406946 & 0.8787 \\
\hline ARCH-LM(9) & 4.662679 & 0.8627 & 3.351652 & 0.9487 & 3.846727 & 0.9212 \\
\hline ARCH-LM(12) & 9.381397 & 0.6701 & 14.02604 & 0.2990 & 12.40703 & 0.4136 \\
\hline
\end{tabular}

Inflation Equation: $\pi_{t}=\alpha_{0} \sqrt{h}_{\mathrm{t}}+\alpha_{1} \pi_{t-1}+\varepsilon_{\mathrm{t}}$

Conditional Variance (ARCH(1)-M): $h_{t}=\lambda_{0}+\lambda_{1} \varepsilon_{t-1}^{2}$

Conditional Variance $(\operatorname{EGARCH}(1,1,1)-\mathrm{M}): \mathrm{H}_{\mathrm{t}}=\lambda_{0}+\lambda_{1}\left|\frac{\varepsilon_{t-1}}{\sqrt{h_{t}}}\right|+\lambda_{2} \mathrm{H}_{\mathrm{t}-1}+\gamma_{1} \frac{\varepsilon_{t-1}}{\sqrt{h_{t}}}$

Conditional Variance (APGARCH(1,1,1)-M): $h_{t}^{\tau}=\lambda_{0}+\lambda_{1}\left(\left|\varepsilon_{t-1}\right|-\gamma_{1} \varepsilon_{t-1}\right)^{\tau}+\lambda_{2} h_{t-1}^{\tau}$

$-\mathrm{ARCH}(1)-\mathrm{M}$ is modelled assuming that the error term follows student-t distribution with fixed degrees of freedom equal 6.

- EGARCH(1,1,1)-M is modelled assuming that the error term follows GED distribution with fixed parameter of 1.5.

- APGARCH(1,1,1)-M is modelled assuming that the error term follows GED distribution with fixed parameter of 4.

* refers to the p-value of the L-jung-Box Q-Stat

Figure (2) shows the generated series of inflation uncertainty resulted from EGARCH(1,1,1)-M model. As shown in the figure, Volatility of inflation has been increased since 2003 after the devaluation of Egyptian pound reflecting the 
pass-through effect of exchange rate on inflation rates which led in turn to higher uncertainty. Additionally, this instability is surged in early 2008 due to the increase in inflation rate at the same time. This rise in inflation rate was due to the existence to some internal shocks that include the supply shocks related to decreasing oil subsidy and the second round-effects of the avian flu. Additionally, the upsurge in the international food prices associated with increasing prices of some oil products in 2008 raised up inflation rate steadily to peak at $22 \%$ at the end of September 2008. Moreover, the expansion in some sectors such as the construction and manufacturing sectors led to accelerate the rates of economic growth that increases inflation expectations that led in turn to this surge in inflation rates. In 2009, the decrease in the world prices of several foodstuffs contributed to declining the inflation rate (Central Bank of Egypt, 2010). Finally, the uncertainty of inflation has significantly surged starting from late 2016 due to the floatation of the Egyptian pound in November 2016.

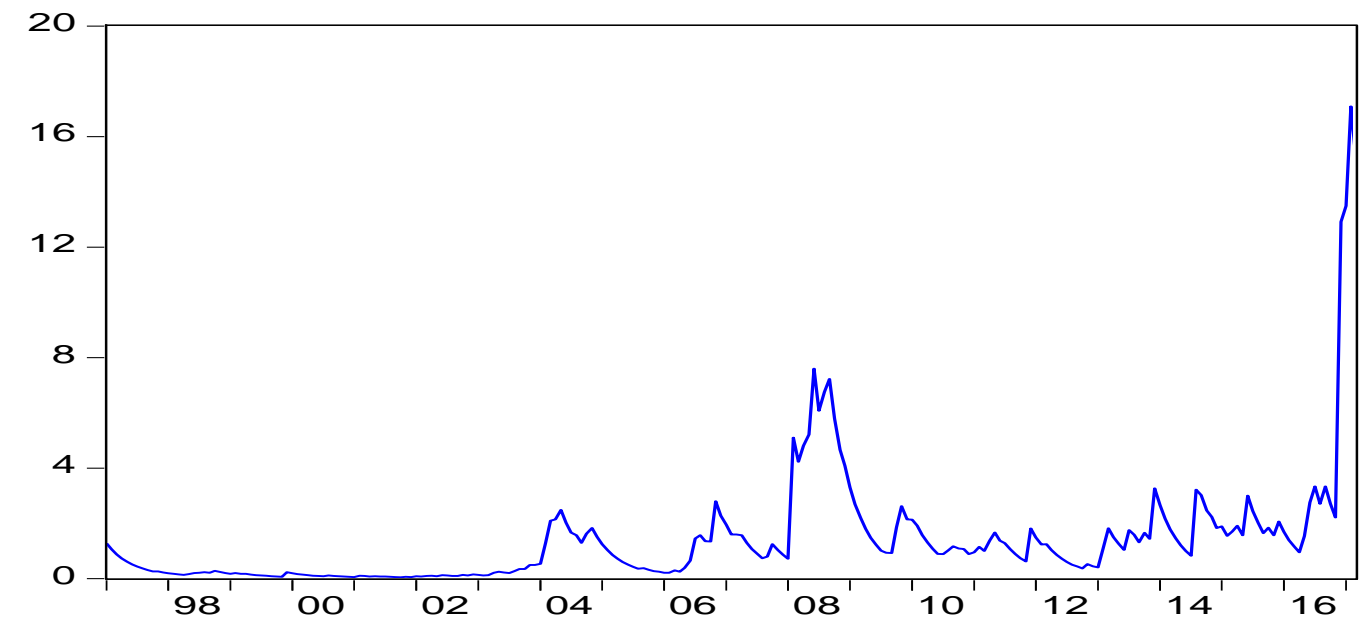

Figure (2). Uncertainty of Inflation during the period 1997:1 - 2017:3

\subsection{Results of Testing Fisher Hypothesis Augmented with Inflation Uncertainty}

This subsection presents the results of MSM that employed to estimate the impact of both inflation and its uncertainty on interest rate. To do this, we estimated to models; the first is the basic model with the original Fisher hypothesis that assumes that expected inflation positively affect interest rate. The second model is the augmented version of Fisher hypothesis that allows the volatility of inflation to have an impact on interest rate. As shown in table (3) the L-Jung-Box $\mathrm{Q}$ test statistic indicates the absence of serial correlation between the estimated residuals. Thus, the two models are well specified and can be used in investigation. Regarding lagged interest rate, it has positive impact in current values of interest rates in both regimes in the two underlying models. In the simple Fisher hypothesis which is displayed in panel A in table (3), expected inflation has a positive and significant impact on interest rate in the first regime while it is insignificant in the second regime. Thus, the estimated relationship changes between different regimes. Given that the estimated coefficient of expected inflation is less than one, the weak from of Fisher hypothesis is satisfied. Thus, the central bank of Egypt raises interest rate in response to the increase in expected inflation that shows a positive risk premium which is important for risk-averse investors.

Panel (B) of table (3) presents the results of the augmented Fisher hypothesis. According to this specification, inflation prediction parameter is positive and less than one, but it is insignificant in the two regimes. This indicates the absence of the causal impact of expected inflation on interest rate which contradicts with the findings of Berument et. al., (2007) concerning the negative link between inflation and interest rate in Egypt. This contradiction could be attributed to the different employed samples as their sample covers the period (1997:01 2004:05). As indicated by Berument et. al., (2007), fisher hypothesis will not be achieved if interest rates are suppressed and are not allowed to move with changes in the predicted inflation. Furthermore, even if the interest rates can freely move in response to changes in expected inflation, this response will be weak if the money markets are not adequately sophisticated.

Regarding the effect of inflation uncertainty on interest rate in the first regime, it is positive and significant entailing that Markowitz's (1952) portfolio hypothesis is advocated. This result is highly important for the central bank as it indicates that if it attempts to reduce inflation by raising interest rate, but it does not enjoy a moderate level of credibility, then applying a contractionary policy will cause expected inflation to be higher compared to the actual level of inflation. This will, in turn, lead to increasing inflation uncertainty that will be reflected in high interest rates. Based on that, the central bank should a follow a policy that reduces both inflation rates and its uncertainty. As indicated by 
Berument (1999), the impact of inflation volatility on interest rate could be used as another channel to investigate the transmission mechanisms of monetary policy on output.

In the second regime, the influence of inflation risks on interest rate is negative and significant which advocates the loanable funds hypothesis during this regime. This could be investigated by the difference between the volatility of inflation and that of nominal income that implies a high volatility of real income. Based on that, the consumers will seek to protect themselves against inflation by raising their savings leading to lower consumption and interest rates. These results confirm the nonlinear relation between the variables under study which justifies employing MSM. Figure (3) depicts the filtered regime probabilities for interest rate Equation. We can notice that for any point the summation of the probabilities in the two regimes is equal to one. In addition, the highest probability belongs to the second regime in the beginning of the period, whereas, the highest probability belongs to the first regime in the end of the studied sample.

Table (3). Results of the interest rate equation

\begin{tabular}{|c|c|c|c|c|c|c|}
\hline \multirow[b]{2}{*}{ Variable } & \multicolumn{3}{|c|}{$\begin{array}{c}\text { Panel A } \\
\text { Simple Fisher Hypothesis }\end{array}$} & \multicolumn{3}{|c|}{$\begin{array}{c}\text { Panel B } \\
\text { Augmented Fisher Hypothesis } \\
\end{array}$} \\
\hline & Coefficient & z-Statistic & Prob. & Coefficient & z-Statistic & Prob. \\
\hline \multicolumn{7}{|c|}{ Regime 1} \\
\hline$\theta_{1}$ & 0.295192 & 0.899438 & 0.3684 & 0.498629 & 1.731804 & 0.0833 \\
\hline$\Theta_{1}$ & 0.940400 & 28.32054 & 0.0000 & 0.941706 & 32.31526 & 0.0000 \\
\hline$\omega_{1}$ & & & & 0.092468 & 1.964317 & 0.0495 \\
\hline$\gamma_{1}$ & 0.039444 & 2.253834 & 0.0242 & 0.001239 & 0.070759 & 0.9436 \\
\hline LOG(SIGMA) & -0.093356 & -1.46847 & 0.1420 & -0.212460 & -4.017120 & 0.0001 \\
\hline \multicolumn{7}{|c|}{ Regime 2} \\
\hline$\theta_{2}$ & -0.089955 & -1.45083 & 0.0000 & -0.051123 & -7.030198 & 0.0000 \\
\hline$\Theta_{2}$ & 0.95012 & 12.5265 & 0.0000 & 0.956077 & 12.280450 & 0.0000 \\
\hline$\omega_{2}$ & & & & -0.015318 & -2.647577 & 0.0081 \\
\hline$\gamma_{2}$ & 0.002936 & 0.835788 & 0.8662 & 0.000168 & 0.168494 & 0.8662 \\
\hline \multirow[t]{2}{*}{ LOG(SIGMA) } & -2.842553 & -19.9137 & 0.0000 & -5.574774 & -28.66035 & 0.0000 \\
\hline & \multicolumn{4}{|c|}{ Transition Matrix Parameters } & & \\
\hline P11-C & 2.155460 & 5.740028 & 0.0000 & 3.024171 & 6.444503 & 0.0000 \\
\hline $\mathrm{P} 21-\mathrm{C}$ & -1.650116 & -4.77119 & 0.0010 & -1.809863 & -3.302332 & 0.0010 \\
\hline $\begin{array}{l}\text { L-Jung-Box Q } \\
\text { test (lag 10) }\end{array}$ & Statistic: 5.7435 & P-value: & & Statistic: 1.0167 & P-value: 1. & \\
\hline
\end{tabular}



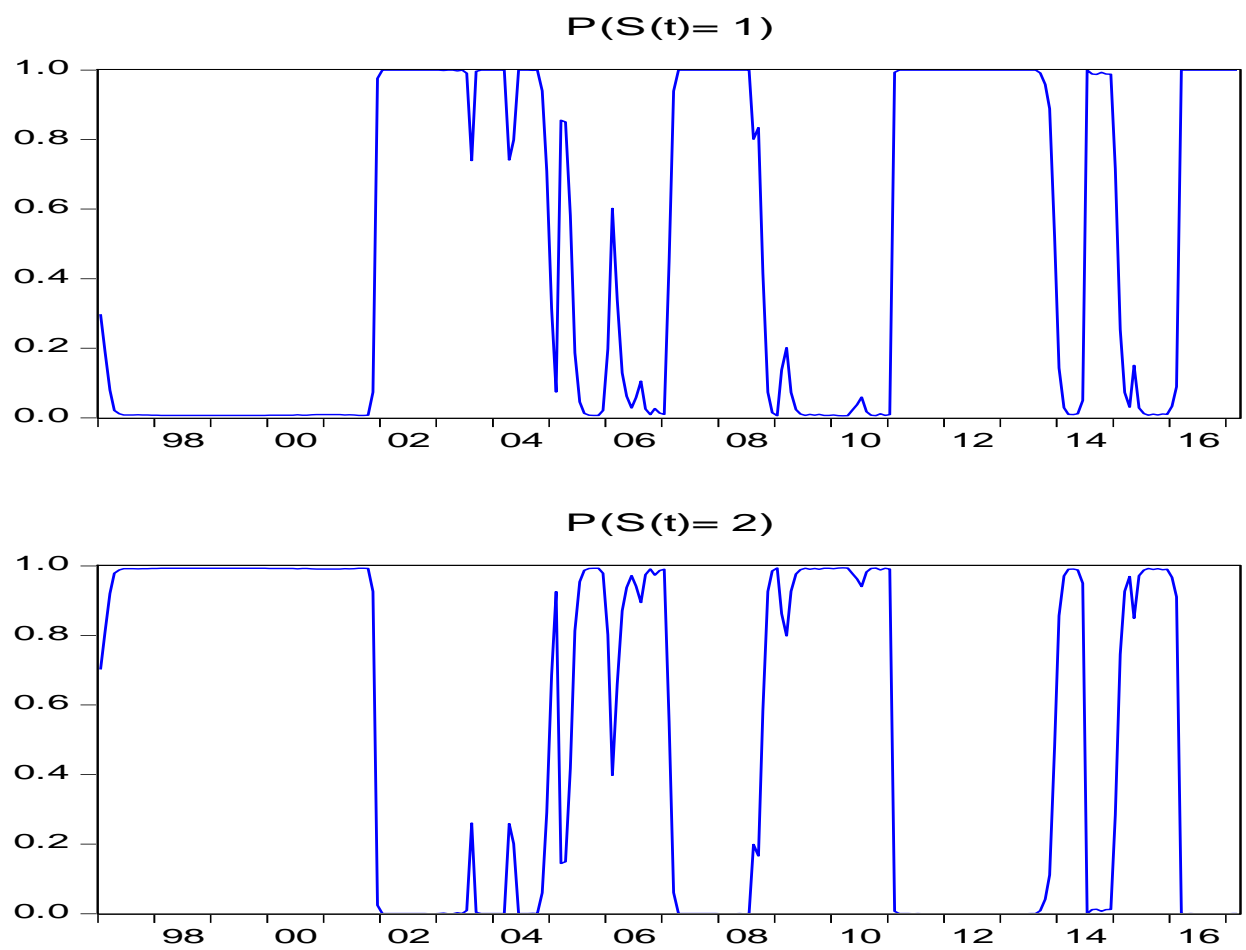

Figure (3). Filtered Regime Probabilities for Interest Rate Equation

As it explained in section 3 we will use Wald test in order to check for the reliability of using MSM rather than the linear regression model. Table (4) depicts Wald test indicates the rejection of the null hypothesis of the same coefficients can be applied in the two regimes. This indicates that MSM is more appropriate than the linear regression model.

Table (4). Wald Test for linearity in MSM

\section{Conclusions}

\begin{tabular}{lccc}
\hline Test Statistic & Value & Degrees of freedomProbability \\
\hline F-statistic & 148.3392 & $(5,230)$ & 0.0000 \\
Chi-square & 741.6960 & 5 & 0.0000 \\
\hline
\end{tabular}

We aimed at investigating an augmented Fisher (1930) hypothesis by incorporating inflation uncertainty directly in the traditional Fisher hypothesis. To model the volatility of inflation, we employed three different ARCH-family models that include the ARCH in mean (ARCH-M), Exponential GARCH in mean (EGARCH(1,1,1)-M) model of Nelson's (1991), and Asymmetric Power GARCH (APGARCH(1,1,1)-M. The EGARCH(1,1,1)-M is favoured over its competitors based on both the AIC and SIC criterion. Then, the simple and modified Fisher (1930) hypothesis are examined by employing a MSM to take into consideration the possibility of structural breaks in the studied variables. Our results indicate the existence of regime shift regarding the effect of inflation risks on Egypt's Treasury bill interest rates during the period (1997:1 2017:3). Thus, in the simple Fisher hypothesis model, we found that predicted inflation has a positive and significant impact on interest rate in the first regime while it is insignificant in the second regime.

In the augmented Fisher hypothesis model, there is no relation between the expected inflation and interest rate in both regimes which is investigated by the weakness of money market that lead to small response of interest rate to changes in anticipated inflation. In contrast, inflation instability positively influences interest rate in the first regime which is in favour of Markowitz's (1952) portfolio theory. The above results are crucial for central bank when employing a tight monetary policy. Thus, if the central bank does not have enough credibility, then, if the central bank follows a contractionary policy, the expected inflation will exceed the actual inflation leading to higher inflation risks. This increase in inflation risks will be reflected on higher interest rates which is another transmission mechanism that could explain how tight monetary policy reduces output. In the second regime, inflation volatility does not have any influence on interest rate which supports the loanable fund theory. These findings confirm that the link between the employed variables is nonlinear which requires using nonlinear models or models that allow the parameters to vary with time.

Given these findings, it is recommended that the central bank works on lowering both inflation and its uncertainty simultaneously to avoid the negative consequences of inflation risks on the economy. Additionally, central bank should devote more efforts to enhance its credibility to avoid the possible adverse consequences of low credibility. This credibility could be achieved by adopting a transparent policy rule that is designed to achieve long-term price stability. Also, central 
bank of Egypt should provide more commitment towards achieving its ultimate goal and stop responding to government pressures to achieve other goals that contradicts with price stability. This paper could be extended to examine the impact of inflation risk on other variables such as exchange rate, domestic credit, stock market, investment and output growth.

\section{References}

Ball, L. (1992). Why Does High Inflation Raise Inflation Uncertainty?. Journal of Monetary Economics, 1, 371-388. https://doi.org/10.1016/0304-3932(92)90032-W

Berument, H. (1999). The Impact of Inflation Uncertainty on Interest Rates in The UK. Scottish Journal of Political Economy, 46, 207-218. https://doi.org/10.1111/1467-9485.00129

Berument, H., Kilinc, Z., \& Ozale, U. (2005). The Missing Link between Inflation Uncertainty and Interest Rates. Scottish Journal of Political Economy, 52, 222-241. https://doi.org/10.1111/j.0036-9292.2005.00342.x

Berument, H., Ceylan, N. B., \& Olgun, H. (2007). Inflation Uncertainty and Interest Rates: Is the Fisher Relation Universal? Applied Economics, 39, 53-68. https://doi.org/10.1080/00036840500427908

Bhar, R., \& Malik, G. (2012). Components of Inflation Uncertainty and Interest Rates: Evidence from Australia and New Zealand. Economic Analysis \& Policy, 42(1). https://doi.org/10.1016/S0313-5926(12)50003-2

Blanchard. (2003). Fiscal Dominance and Inflation Targeting: Lessons from Brazil. Unpublished Manuscript, MIT Department of Economics. Doi: 10.2139/ssrn.518265. https://doi.org/10.2139/ssrn.518265

Bollerslev, T. (1986). Generalized Autoregressive Conditional Heteroscedasticity. Journal of Econometrics, 31, 307-327. https://doi.org/10.1016/0304-4076(86)90063-1

Bomberger, W. A., \& Frazer, W. J. (1981). Interest Rates, Uncertainty and the Livingston Data. Journal of Finance, 36, 661-675. https://doi.org/10.1111/j.1540-6261.1981.tb00651.x

Brunner, A., \& Hess, G. (1993). Are Higher Levels of Inflation Less Predictable? A State-Dependent Conditional Heteroscedasticity Approach. Journal of Business \& Economic Statistics, 11(2), 187-97. https://doi.org/10.1080/07350015.1993.10509947

Central Bank of Egypt. (2010). Economic Review (2010), 50(3), (Online) Available at: http://www.cbe.org.eg/Publications.html

Clark, T. E. (1997). Cross-country Evidence on Long-run Growth and Inflation. Economic Inquiry, 35, $70-81$. https://doi.org/10.1111/j.1465-7295.1997.tb01895.x

Chan, L. (1994). Consumption, Inflation Risk, and Real Interest Rates: An Empirical Analysis. Journal of Business, 67, 69-96. https://doi.org/10.1086/296624

Cukierman, A., \& Meltzer, A. (1986). A Theory of Ambiguity, Credibility, and Inflation under Discretion and Asymmetric Information. Econometrica, 17, 1099-1128. https://doi.org/10.2307/1912324

Darvas, Z., \& Varga, B. (2009). Time-Varying Coefficient Methods to Measure Inflation Persistence (No. 259600167). EcoMod. https://ecomod.net/sites/default/files/document-conference/ecomod2010/1344.pdf

Davis, G., \& Kanogo, B. (1996). On Measuring the Effect of Inflation Uncertainty on Real GNP Growth. Oxford Economic Papers, 48, 163-175. https://doi.org/10.1093/oxfordjournals.oep.a028558

Ding, Z., Granger, C. W. J., \& Engle, R. F. (1993). A Long Memory Property of Stock Market Returns and A New Model. Journal of Empirical Finance, 1, 83-106. https://doi.org/10.1016/0927-5398(93)90006-D

Dotsey, M., \& Sarte, P. (2000). Inflation Uncertainty and Growth in a Cash-in-Advance Economy. Journal of Monetary Economics 45, 3, 631-655. https://doi.org/10.1016/S0304-3932(00)00005-2

Elder, J. (2004). Another Perspective on the Effects of Inflation Uncertainty. Journal of Money, Credit and Banking, 36(5), 911-928. https://doi.org/10.2139/ssrn.262182

Engle, R. (1982). Autoregressive Conditional Heteroscedasticity with Estimates of the Variance of UK Inflation. Econometrica, 50, 267-287. https://doi.org/10.2307/1912773

Friedman, M. (1977). Nobel Lecture: Inflation and Unemployment. Journal of Political Economy, 85, 452-472. https://doi.org/10.1086/260579

Fountas, S., Ioannidis, A., \& Karanasos, M. (2004). Inflation, Inflation Uncertainty and a Common European Monetary Policy. The Manchester School, 72(2), 221-242. https://doi.org/10.1111/j.1467-9957.2004.00390.x

Grier, K., \& Perry, M. J. (1998). On Inflation and Inflation Uncertainty in the G7 Countries. Journal of International Money and Finance, 17, 671-689. https://doi.org/10.1016/S0261-5606(98)00023-0 
Grier, K., \& Perry, M. J. (2000). The Effects of Real and Nominal Uncertainty on Inflation and Output Growth: Some GARCH-M Evidence. Journal of Applied Econometrics, $15, \quad 45-58$. https://doi.org/10.1002/(SICI)1099-1255(200001/02)15:1<45::AID-JAE542>3.0.CO;2-K

Hafer, R. W. (1986). Inflation Uncertainty and a Test of the Friedman Hypothesis. Journal of Macroeconomics, 8, 365-372. https://doi.org/10.1016/0164-0704(86)90067-4

Hamilton, J. D. (1989). A New Approach to the Economic Analysis of Nonstationary Time Series and the Business Cycle. Econometrica, 57, 357-384. https://doi.org/10.2307/1912559

Hamilton, J. D. (1994). Time Series Analysis. Princeton University Press, Princeton, NJ.

Hayford, M. D. (2000). Inflation Uncertainty, Unemployment Uncertainty and Economic Activity. Journal of Macroeconomics, 22, 315-29. https://doi.org/10.1016/S0164-0704(00)00134-8

Huang, Y. C., \& Lin, B. (2004). Value-at-risk analysis for Taiwan stock index futures: fat tails and conditional asymmetries in return innovations. Review of Quantitative Finance and Accounting, 22(2), 79-95. https://doi.org/10.1023/B:REQU.0000015851.78720.a9

Hess, G. D., \& Brunner, A. D. (1993). Are higher levels of Inflation Less Predictable? A state Dependent Conditional Heteroscedasticity Approach. Journal of Business and Economic Statistics, 11, 187-197.

Holland, S. (1995). Inflation and Uncertainty: Tests for Temporal Ordering. Journal of Money, Credit, and Banking 27(3), 827-837. https://doi.org/10.2307/2077753

Javed, S. A., \& Khan, S. A. (2010). Inflation and Inflation Uncertainty: A GARCH Application - An Appraisal from Pakistan. International Conference on Applied Economics. https://doi.org/10.2307/2077753

Juster, F. T., \& Taylor, D. (1975). Towards a Theory of Saving Behaviour. American Economic Review, 65, 203-209. https://doi.org/10.1016/j.riob.2015.10.002

Juster, F. T., \& Wachtel, P. (1972a). Inflation and the Consumer. Brookings Papers, 1, 71-114. https://doi.org/10.2307/2534115

Juster, F. T., \& Wachtel, P. (1972b). A Note on Inflation and the Saving Rate. Brookings Papers, 3, 765-778. https://doi.org/10.2307/2534131

Kandel, S., Ofer, A., \& Sarig, O. (1996). Real Interest Rates and Inflation: An Ex-ante Empirical Analysis. The Journal of Finance, 60, 205-225. https://doi.org/10.1111/j.1540-6261.1996.tb05207.x

Karanasos, \& Schurer. (2008). Is the Relationship between Inflation and Its Uncertainty Linear?. German Economic Review, 9(3), 265-286. https://doi.org/10.1111/j.1468-0475.2008.00433.x

Levin, R., \& Renelt, D. (1992). A Sensitivity Analysis of Cross-Country Growth Regressions. American Economic Review, 82, 942-963. doi: 10.12691/ijefm-4-1-1

Levin, R., \& Zervos, S. (1993). What Have We Learned about Policy and Growth from Cross-country Analysis?. American Economic Review Papers and Proceedings, 83, 426-430.

Mallik, G., \& Bhar, R. (2011). Has the Link between Inflation Uncertainty and Interest Rates Changed after Inflation Targeting?. Journal of Economic Studies, 38(6), 620-636. https://doi.org/10.1108/01443581111177358

Markowitz, H. (1952). Portfolio Selection. Journal of Finance, 7, 77-91. http://doi/10.1111/j.1540-6261.1952.tb01525.x

Mishkin, F. S. (1992). Is the Fisher Effect for Real? A Re-examination of the Relationship between Inflation and Interest Rates. Journal of Monetary Economics, 30, 195-215. https://doi.org/10.1016/0304-3932(92)90060-F

Nelson, D. B. (1991). Conditional Heteroscedasticity in Asset Returns: A New Approach. Econometrica, 59(2), 347-370. https://doi.org/10.2307/2938260

Omay, T., \& Hasanov, M. (2010). The Effects of Inflation Uncertainty on Interest Rates: a Nonlinear Approach. Applied Economics, 42, 2941-2955. https://doi.org/10.1080/00036840801964757

Pourgerami, A., \& Maskus, K. (1987). The Effects of Inflation on the Predictability of Price Changes in Latin America: Some Estimates and Policy Implications. World Development 15(2), 287-290. https://doi.org/10.1016/0305-750X(87)90083-0

Sarte, P. D. G. (1998). Fisher's Equation and the Inflation Risk Premium in a Simple Endowment Economy. Economic Quarterly, Federal Reserve Bank of Richmond, Fall, 53-72. http://doi=10.1.1.198.3055\&rep=rep1\&type=pdf

Schwert, W. (1989). Stock Volatility and Crash of 87. Review of Financial Studies. 3, 77-102. https://doi.org/10.1093/rfs/3.1.77 
Stulz, R. M. (1986). Interest Rates and Monetary Policy Uncertainty. Journal of Monetary Economics, 17, 331-347. https://doi.org/10.1016/0304-3932(86)90061-9

Taylor, S. (1986). Modeling Financial Time Series, New York: John Wiley \& Sons.

Tzavalis, E., \& Wickens, M. R. (1996). Forecasting Inflation from the Term Structure. Journal of Empirical Finance, 3, 103-122. https://doi.org/10.1016/0927-5398(95)00021-6

Ungar, M., \& Zilberfarb, B. (1993). Inflation and its Unpredictability - Theory and Empirical Evidence. Journal of Money, Credit, and Banking, 25(4), 709-720. https://doi.org/10.2307/2077800

Wilson, B. K. (2006). The Link between Inflation, Inflation Uncertainty and Output Growth: New Time Series Evidence from Japan. Journal of Macroeconomics, 28, 609-620. https://doi.org/10.1016/j.jmacro.2004.11.004

Wilson, B. K., \& Culver, S. E. (1999). On Measuring the Response of Real GDP Growth to Change in Inflation Volatility. Quarterly Journal of Business and Economics, 38(3). http://www.jstor.org/stable/40473274

Yuhn, K. H. (1996). Is the Fisher Effect Robust? Further Evidence. Applied Economics Letters, 3, 41-44. https://doi.org/10.1080/758525514

Zilberfarb, B. Z. (1989). Interest Rate Determination in a High Inflation Economy. Journal of Macroeconomics, 11, 533-549. https://doi.org/10.1016/0164-0704(89)90004-9

Živkov, D., Njegić, J., \& Pećanac, M. (2015). Bidirectional linkage between inflation and inflation uncertainty-the case of Eastern European countries. Baltic Journal of Economics, 14, 1-16. https://doi.org/10.1016/0164-0704(89)90004-9

\section{Copyrights}

Copyright for this article is retained by the author(s), with first publication rights granted to the journal.

This is an open-access article distributed under the terms and conditions of the Creative Commons Attribution license which permits unrestricted use, distribution, and reproduction in any medium, provided the original work is properly cited. 